\title{
Microstructural properties of Nb-Si based alloys manufactured by powder metallurgy
}

\author{
S. Drawin ${ }^{1, a}$, J.P. Monchoux ${ }^{2, b}$, J.L. Raviart ${ }^{1, c}$, A. Couret ${ }^{2, d}$ \\ ${ }^{1}$ ONERA, DMSM, 29 avenue de la Division Leclerc, BP72, 92322 Châtillon Cedex, France \\ ${ }^{2}$ CEMES, 29 rue Jeanne Marvig, BP 94347, 31055 Toulouse Cedex 4, France \\ a drawin@onera.fr, ${ }^{\mathrm{b}}$ monchoux@cemes.fr, ${ }^{\mathrm{c}}$ raviart@onera.fr, ${ }^{\mathrm{d}}$ couret@cemes.fr
}

Key words: Niobium; Silicide; Powder Metallurgy; Extrusion; Spark Plasma Sintering.

\begin{abstract}
An NbTiHfCrAlSi niobium silicide based atomized powder has been compacted by a conventional technique (hot extrusion) and by spark plasma sintering to nearly fully dense alloys. Both materials exhibit a metastable fine micrometer-sized microstructure that has been coarsened by a subsequent heat treatment. The densification of the SPS sample takes place between ca. $800^{\circ} \mathrm{C}$ and $1300^{\circ} \mathrm{C}$.
\end{abstract}

\section{Introduction}

Niobium silicide based alloys have gained increasing interest in the past twenty years as candidate materials for turbine components in aero-engines due to their potential to withstand harsh service conditions at temperatures above $1200^{\circ} \mathrm{C}[1-3]$.

The manufacturing route used for these alloys is generally ingot metallurgy [4], which includes arc melting, the easiest technique to produce metallic and intermetallic alloys, and plasma melting as well as directional solidification (DS), such as Czochralsky growth method and zone melting. Castings obtained by ingot metallurgy exhibit an heterogeneous microstructure consisting of large metal ( $\mathrm{Nb}$ solid solution) or intermetallic (niobium based silicides) dendrites and eutectic cells with micrometer-sized $\mathrm{Nb}$ and intermetallic phases. The heterogeneity can be reduced in some extent by subsequent hot working or heat treatments. Furthermore, the microstructure cannot be controlled easily, and the nature and amount of the various phases are directly linked to the initial composition.

The powder metallurgy (PM) route allows additional degrees of freedom that can enhance the homogeneity of the alloy, in terms of both chemical composition and microstructure, and may allow manufacture of dense and near net shape components using conventional techniques (sintering, hot uniaxial or isostatic pressing...): this has been successfully applied to nickel based superalloys, steels, refractory materials and many more.

Up to now, the PM route has been seldom applied to Nb-Si based alloys, probably because of the difficulty to manufacture or buy laboratory scale batches (several $\mathrm{kg}$ ) of powders with experimental (i.e. non commercial) compositions, exhibiting melting points in excess of $1700^{\circ} \mathrm{C}$. One other reason may be the expected higher costs, compared to those of the ingot metallurgy routes, related to the long duration and high temperature treatments required by the conventional compaction techniques. However, new powder compaction techniques, such as spark plasma sintering (SPS), have emerged recently and could be suited to cost-effective manufacture of shaped $\mathrm{Nb}$-Si based parts. SPS combines uniaxial pressing with a rapid internal Joule heating of the metallic powder by means of a pulsed DC current; typical heating rates are $100^{\circ} \mathrm{C} \mathrm{min}^{-1}$, dwell times are only few minutes, so that a dense specimen can be obtained in about one hour, including cooling duration.

The investigation of $\mathrm{Nb}$-Si based alloy manufactured by SPS has up to now been limited to binary and occasionally ternary $(\mathrm{NbSiB}, \mathrm{NbSiAl}, \mathrm{NbSiN})$ compositions [5-9]. Starting materials are either elemental or $\mathrm{Nb}$ and $\mathrm{Nb}_{5} \mathrm{Si}_{3}$ powder mixtures; in the former case, reactive sintering is aimed, and the powders are mixed in stoichiometric proportions according to the reaction: $(1+4 x) \mathrm{Nb}+$ $3 x \mathrm{Si} \rightarrow(1-\mathrm{x}) \mathrm{Nb}+x \mathrm{Nb}_{5} \mathrm{Si}_{3}$, where $x$ is the mole fraction of the silicide phase. The PM route for 
complex alloy compositions (more than two or three elements) has been scarcely investigated, although encouraging results have been obtained, for pre-alloyed isostatically hot pressed powders and reactive sintering of elemental powder mixtures followed by extrusion [10]. Reactive sintering is however not easy to control, and the use of pre-alloyed powders is to be favoured.

In the present paper, the SPS compaction behaviour of a Nb-Si based powder with complex composition (NbTiHfCrAlSi) is investigated for the first time. The microstructure of the SPS sample is compared to that obtained by a conventional compaction technique (hot extrusion). This study is a part of a wider programme that explores the microstructural, mechanical and environmental properties of PM manufactured $\mathrm{Nb}$-Si based parts (especially by SPS) for medium and high temperature applications.

\section{Experimental}

The nominal composition of the studied alloy, with reference N236, is Nb-25Ti-8Hf-2Al-2Cr-16Si (all compositions are in at.\%, unless otherwise stated). This type of alloy combines a $\mathrm{Nb}$ solid solution $\left(\mathrm{Nb}_{\mathrm{ss}}\right)$, and tetragonal tP32 $\mathrm{Nb}_{3} \mathrm{Si}$ and hexagonal hp16 $\mathrm{Nb}_{5} \mathrm{Si}_{3}$ type silicide phases, when manufactured by arc-melting or Czochralsky growth [11]; Ti and $\mathrm{Hf}$ partially substitute for $\mathrm{Nb}$; $\mathrm{Cr}$ and $\mathrm{Al}$ partition strongly to $\mathrm{Nb}_{\mathrm{ss}}$, and $\mathrm{Hf}$ to the silicide phases. The hexagonal $\mathrm{Nb}_{5} \mathrm{Si}_{3}$ forms preferentially the tetragonal $\mathrm{t} 32 \mathrm{Nb}_{5} \mathrm{Si}_{3}$ when high amounts of $\mathrm{Ti}$ and/or $\mathrm{Hf}$ are used in place of $\mathrm{Nb}$.

A $8 \mathrm{~kg}$ ingot has been prepared in a plasma melter from high purity (99.9 to $99.99 \mathrm{wt} . \%$, except $\mathrm{Cr}, 96.6 \mathrm{wt} . \%)$ elemental material. The oxygen content in the ingot has been measured to be less than $1000 \mu \mathrm{g} / \mathrm{g}$. Several bars have been machined from the ingot and subsequently electrode induction gas atomized by a sub-contractor, using argon. The powder has then been sieved into fourteen particle size classes; about $80 \%$ of the powder mass is from particles with size in the range $25 \mu \mathrm{m}-180 \mu \mathrm{m}$. Two powder blends have finally been prepared with particle sizes in the range $45 \mu \mathrm{m}-75 \mu \mathrm{m}$ and $75 \mu \mathrm{m}-125 \mu \mathrm{m}$. The alloy composition was determined by inductively coupled plasma - optical emission spectroscopy (ICP-OES) analysis.

Two techniques have been used to compact the powder: extrusion and SPS. In the first case, the powder $(45 \mu \mathrm{m}-75 \mu \mathrm{m}$ blend) was canned under secondary vacuum in a stainless steel cylinder with a $45 \mathrm{~mm}$ external diameter; a molybdenum alloy sleeve was used to avoid reaction between the powder and the steel can. The can was placed during $15 \mathrm{~min}$ in a furnace at $1400^{\circ} \mathrm{C}$ and extruded with a $6: 1$ ratio and a ram speed of $5 \mathrm{~mm} / \mathrm{s}$ to yield a $19 \mathrm{~mm}$ diameter bar. The diameter of the compacted inner part was ca. $11 \mathrm{~mm}$. The material is referenced as N236-E.

A SPS-Syntex Dr Sinter 2080 SPS facility operated by PNF2/CNRS (Plateforme Nationale de Frittage Flash) in Toulouse, France has been used. Graphite dies were filled with the N236 powder (75 $\mu \mathrm{m}-125 \mu \mathrm{m}$ blend) and closed by two graphite punches; this allows the applied electric current to flow through both the powder and the die. The die was wrapped in a carbon felt for thermal insulation. A force was applied on the punches to help compaction. Graphite foils were placed between powder and tooling to avoid tooling degradation and for easier demoulding. Two sample sizes have been manufactured, having a diameter of $8 \mathrm{~mm}$ or $15 \mathrm{~mm}$, and a thickness of $8 \mathrm{~mm}$, with references N236-S8 and N236-S15. The powder was heated using the automatic temperature control mode at $100^{\circ} \mathrm{C} / \mathrm{min}$ to the maximum temperature $\left(1300^{\circ} \mathrm{C}\right.$ for $\mathrm{N} 236-\mathrm{S} 8,1250^{\circ} \mathrm{C}$ for $\left.\mathrm{N} 236-\mathrm{S} 15\right)$ which was held for $2 \mathrm{~min}$. The force, corresponding to a pressure of $75 \mathrm{MPa}$, was applied simultaneously to the current. The temperature was measured by a pyrometer on the external surface of the die; the settings corresponded to $c a .1325^{\circ} \mathrm{C}$ at the centre of the sample. The temperature at this location was estimated to be about $25^{\circ} \mathrm{C}$ and $50^{\circ} \mathrm{C}$ higher than the temperature measured by the pyrometer for the $8 \mathrm{~mm}$ and $15 \mathrm{~mm}$ dies, respectively, based on the current and temperature field simulation by the finite elements method performed for intermetallic (TiAl) and ceramic $\left(\mathrm{Al}_{2} \mathrm{O}_{3}\right)$ materials, together with metallographic investigations [12].

Heat treatments were performed in an argon atmosphere (99.999\% pure) in a furnace that was first pumped to a $10 \mathrm{~Pa}$ range vacuum. 
Samples for microstructural investigation were cut by electrode discharge machining, avoiding the near surface areas where possible contaminations by metals (extruded sample) or carbon (SPS sample) can be found. Zeiss scanning electron microscopes (with and without field emission gun) were used mainly in backscattered electron (BSE) mode and standardless energy dispersive spectrometry (EDS) was used for local composition measurements. Image analysis was performed to estimate the surface fraction of phases and pores.

\section{Results and Discussion}

The actual composition of the overall powder of the two blends is given in Table 1. The low Si content $(\sim 15.2$ at.\%) is due to the procedure used for the multiple plasma meltings, where niobium bars had to be used to fix the material that is moved into the plasma torch, this additional niobium being (partly) compensated by additional amounts of the other elements. The $\mathrm{Ti}, \mathrm{Hf}, \mathrm{Cr}$ and $\mathrm{Al}$ contents are independent of the particle size class (within the experimental uncertainties); but the analyses show a trend of slightly higher $\mathrm{Si}$ contents (and lower $\mathrm{Nb}$ contents) for larger particle size class. The oxygen content of the powder is similar to that of the bulk ingot.

Table 1 - Composition of the powder measured by ICP-OES [at\%]

\begin{tabular}{|c|c|c|c|c|c|c||c|}
\hline Element & $\mathrm{Nb}$ & $\mathrm{Ti}$ & $\mathrm{Hf}$ & $\mathrm{Cr}$ & $\mathrm{Al}$ & $\mathrm{Si}$ & $\mathrm{O}[\mu \mathrm{g} / \mathrm{g}]$ \\
\hline Nominal & 47 & 25 & 8 & 2 & 2 & 16 & - \\
\hline Overall & $\begin{array}{c}47.2 \\
( \pm 0.3)\end{array}$ & $\begin{array}{c}25.4 \\
( \pm 0.2)\end{array}$ & $\begin{array}{c}7.5 \\
( \pm 0.1)\end{array}$ & $\begin{array}{c}1.9 \\
( \pm 0.02)\end{array}$ & $\begin{array}{c}2.2 \\
( \pm 0.02)\end{array}$ & $\begin{array}{c}15.2 \\
( \pm 0.1)\end{array}$ & $\begin{array}{c}1100 \\
( \pm 200)\end{array}$ \\
\hline $45 \mu \mathrm{m}-75 \mu \mathrm{m}$ blend & 47.6 & 25.3 & 7.5 & 1.9 & 2.2 & 15.0 & 1000 \\
\hline $75 \mu \mathrm{m}-125 \mu \mathrm{m}$ blend & 47.2 & 25.5 & 7.6 & 1.9 & 2.2 & 15.2 & 950 \\
\hline
\end{tabular}

The microstructure of the as-atomized powder, taking the $45 \mu \mathrm{m}-75 \mu \mathrm{m}$ blend as an example (the $75 \mu \mathrm{m}-125 \mu \mathrm{m}$ blend showing similar features), is shown in Fig. 1. If particles occasionally exhibit a smooth appearance, most reveal a structured surface. Cross-sectional views (Fig. 1-b and c) show that the cooling rate during atomization is low enough to allow a dentritic microstructure to establish from the molten state, with the dendrites' size growing from particle's edge to the core (Fig. 1-c) where the cooling rate is the lowest. The size of the dendrites remains however about one order of magnitude lower than what is encountered in arc-melted samples [11]. The dendrites are identified as niobium silicide, showing that the alloy is hypereutectic despite the low Si content. No major changes in the microstructure are noticed that would indicate a drastic variation of the $\mathrm{Si}$ content (presence of $\mathrm{Nb}_{\mathrm{ss}}$ dendrites, low surface fraction of eutectic, etc.). The particles contain some micrometer-sized pores (Fig. 1-b and -c), but with a low surface density.

The microstructure of the N236-E material is shown in Fig. 2. Longitudinal and transverse sections exhibit very similar features. However, there is a difference between the centre and the edge of the bar. In the former, the pore surface fraction, as measured by image analysis, is less than $0.15 \%$ with a low amount of bigger pores $(<1.5 \mu \mathrm{m}$ in diameter). In the latter, the porosity level can be higher than $1 \%$, with pore diameters larger than $5 \mu \mathrm{m}$, because of the intense shearing at the Nb$\mathrm{Si}$ alloy / Mo alloy sleeve interface during extrusion. The mean particle size is about $1 \mu \mathrm{m}$, which is too small to be precisely analysed by EDS; the trend is however that the brighter the grey level, the higher the Si content (because of a higher Hf content). X-ray diffraction analysis has shown that only $\mathrm{Nb}_{\mathrm{ss}}$ and $\mathrm{hp} 16 \mathrm{Nb}_{5} \mathrm{Si}_{3}$ were present in the centre of the plasma melted ingot, which indicates that the eutectoid decomposition of $\mathrm{Nb}_{3} \mathrm{Si}$ into $\mathrm{Nb}_{\mathrm{ss}}$ and $\mathrm{Nb}_{5} \mathrm{Si}_{3}$ had time to occur. Because the alloy is remelted during atomization, this phase combination is lost and the out-of-equilibrium phase mixture $\mathrm{Nb}_{\mathrm{ss}}+\mathrm{Nb}_{3} \mathrm{Si}+\mathrm{Nb}_{5} \mathrm{Si}_{3}$ is expected in the powder. This combination is retained after extrusion, since the phases with intermediate (15-25 at \%) and high (30-40 at $\%)$ Si contents are detected in the extruded samples. A non negligible number of large silicide particles with sizes up to 


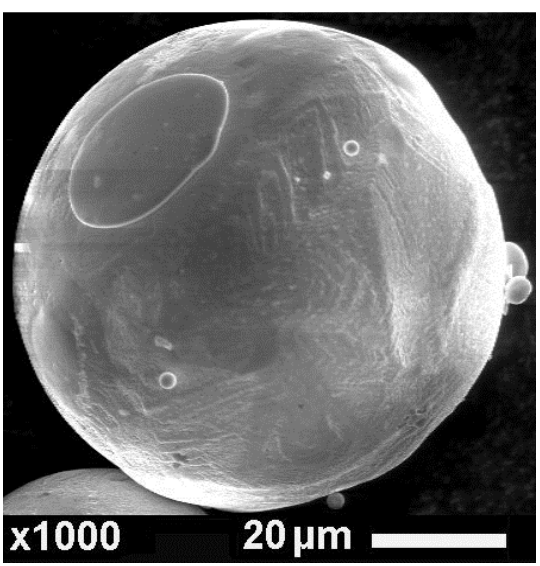

(a)

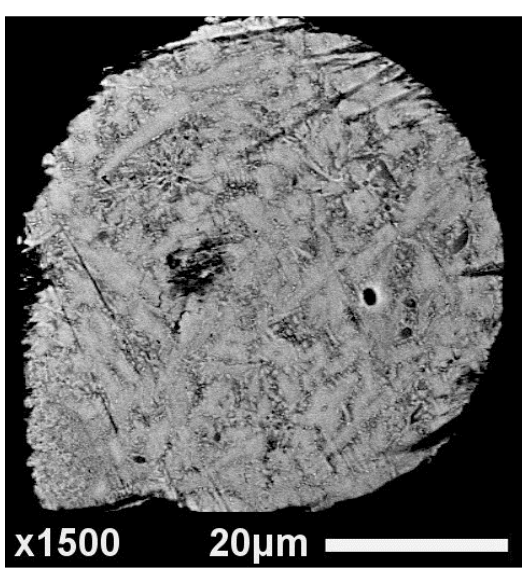

(b)

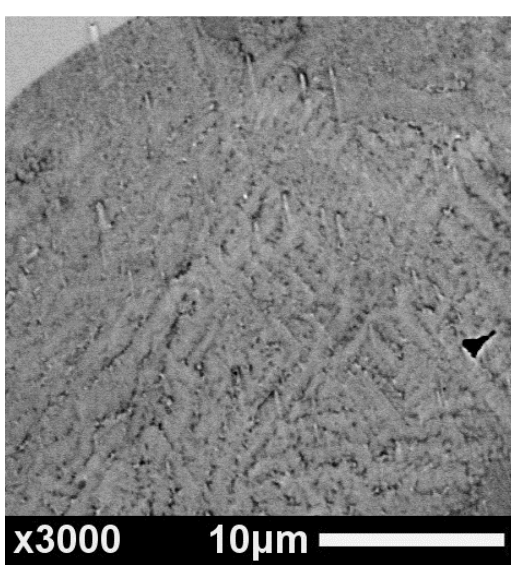

(c)

Fig. 1 - Microstructure of the as-atomized powder $(45 \mu \mathrm{m}-75 \mu \mathrm{m}$ blend): surface (a), cross-section (b, c).

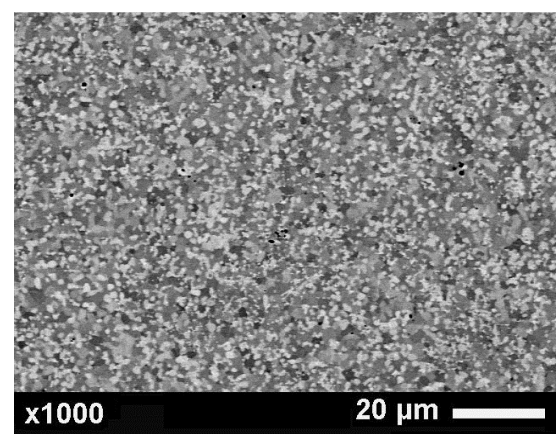

(a)

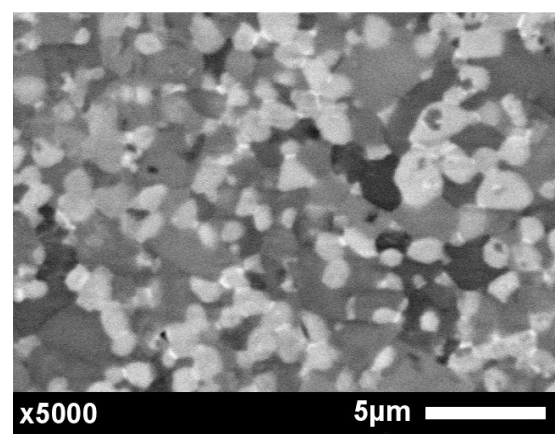

(b)

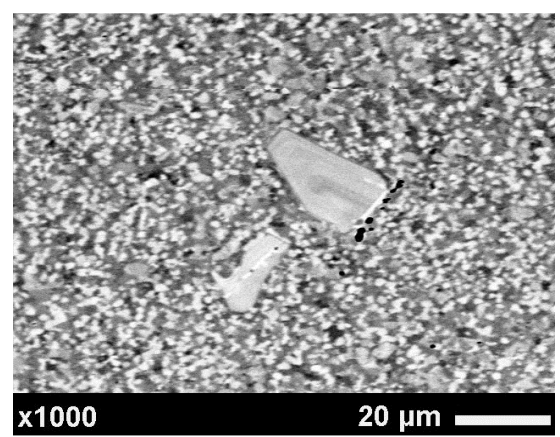

(c)

Fig. 2 - Transverse section in the bulk of N236-E (extruded at $1400^{\circ} \mathrm{C}$ ), at two magnifications.

$50 \mu \mathrm{m}$ are found throughout the material (Fig. 2-c), due to an incomplete melting during atomization. Compared to materials obtained by reactive sintering [10], Nb236-E exhibits a finer and more homogeneous microstructure.

A part of the extruded bar has been heat treated at $1400^{\circ} \mathrm{C}$ for $24 \mathrm{~h}$. The resulting microstructure is illustrated in Fig. 3. The comparison of Fig. 3-a with Fig. 2-a shows that the microstructure has coarsened significantly with an increase of the grain size by a factor five to ten. Three bulky phases are present: the dark phase is a Ti-rich, Hf-poor $\mathrm{Nb}_{\mathrm{ss}}$, with approximate composition $55 \mathrm{Nb}-28 \mathrm{Ti}-$ 7Hf-3Cr-6Al-1Si, the grey phases are both $\mathrm{Nb}_{5} \mathrm{Si}_{3}$, the light grey phase being $\mathrm{Nb}$-poor and Hf-rich (19.5Nb-22Ti-17Hf-0.2Cr-2.3Al-39Si) and the medium grey phase being Nb-rich as well as Hf- and Si-poor (32Nb-18Ti-13Hf-0.2Cr-1.3Al-35.5Si). Small elongated particles (width: $0.1 \mu \mathrm{m}$ to $0.4 \mu \mathrm{m}$ ) are sometimes detected between two Hf-rich $\mathrm{Nb}_{5} \mathrm{Si}_{3}$ particles; they exhibit a high content of hafnium, and are possibly hafnia based phases, as Hf is known in this type of materials to be an oxygen scavenger [11].

The evolution of the main parameters in the SPS manufacturing cycle is shown in Fig. 4. Geometrical particle arrangement takes place at low temperature, without plastic deformation; this is followed by sintering and plastic deformation of the $\mathrm{Nb}_{\mathrm{ss}}$ phase at temperatures above $\mathrm{ca} .800^{\circ} \mathrm{C}$; the maximum compaction, in terms of punch displacement, is obtained slightly before the plateau temperature is reached. Fig. 4 shows also that a high electrical power (up to $80 \%$ of the power needed to maintain the plateau temperature) flows through the device in the first minute (current up to $300 \mathrm{~A}$ ): hence, the small cross-sectional inter-particle contact area can exhibit high current densities (note however that the electrical resistivity of the powder is higher than that of the die, so that only a fraction of the current flows through the powder). Thus, local temperatures can be considerably higher in the bulk of the particles than on the die surface seen by the pyrometer. 
The N236-S8 and N236-S15 samples, manufactured by SPS, exhibit similar microstructural features, but these are significantly different compared to N236-E, as shown in Fig. 5. The material is nearly fully dense, with an overall porosity level lower than $0.1 \%$. The microstructure is less homogeneous, with regions with either fine or coarser grain sizes (Fig. 5-a and -b). The coarser microstructure is particularly encountered at the prior particles boundaries (Fig. 5-b). These regions have two characteristics: the first is that they are the contact zones between initial particles, where the transient temperature can be considerably higher than temperature read by the pyrometer. This may explain the fact that, despite the short stay at high temperature (as given by the pyrometer), phase growth and coalescence has begun (compare the wormlike microstructure of Fig. 5-c with Fig. 2-b) but has not yet reached the state exhibited in Fig. 3-c.

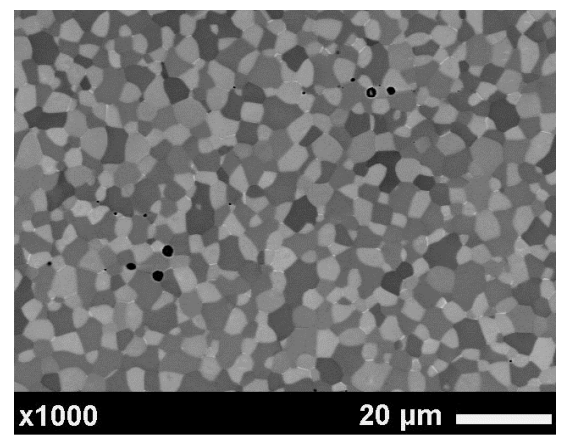

(a)

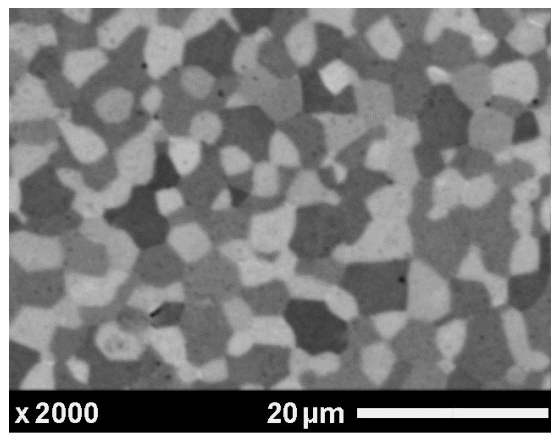

(b)

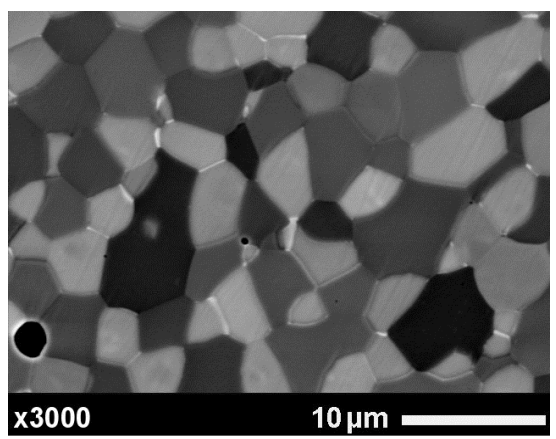

(c)

Fig. 3 - Transverse section of N236-E heat treated at $1400^{\circ} \mathrm{C}$ for $24 \mathrm{~h}$, at various magnifications.

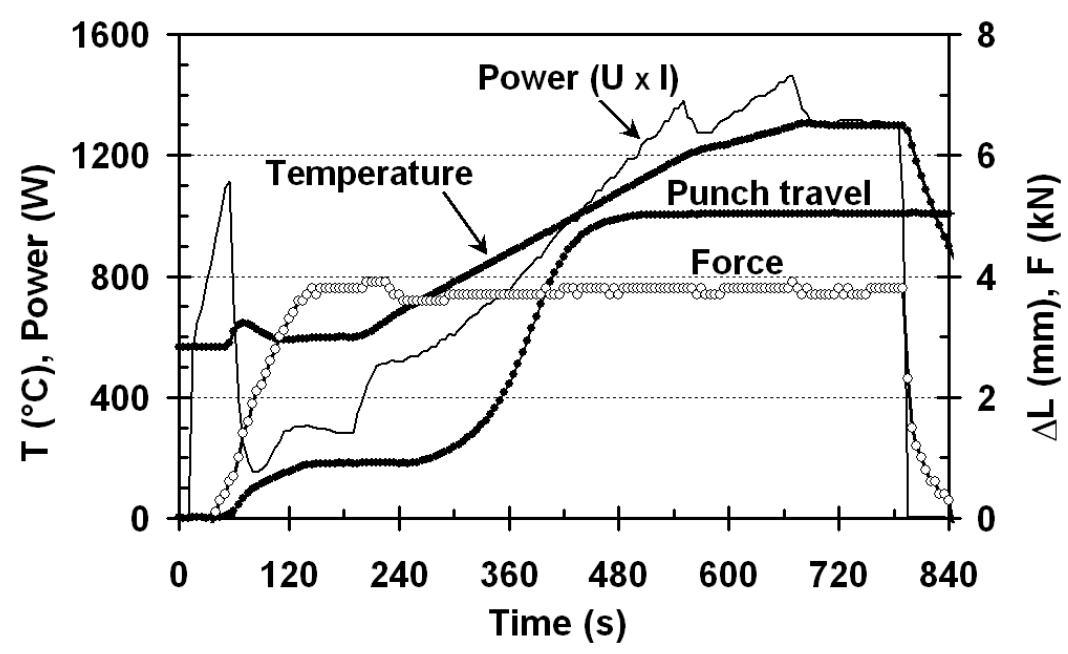

Fig. 4 - Evolution of measured temperature $T$ (the pyrometer is operative only above $600^{\circ} \mathrm{C}$ ), injected electrical power (current $\times$ voltage), punch travel $\Delta L$ and force $F$ during the N236-S8 SPS cycle.

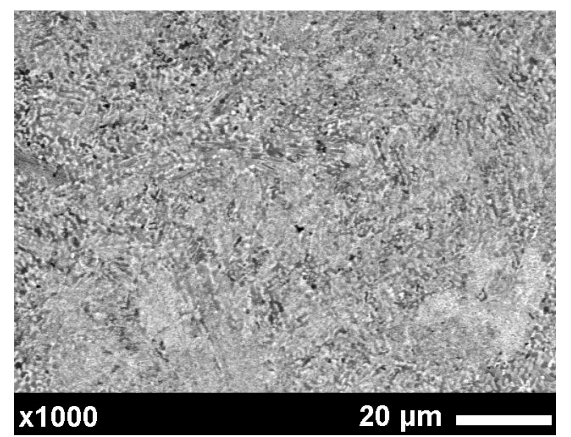

(a)

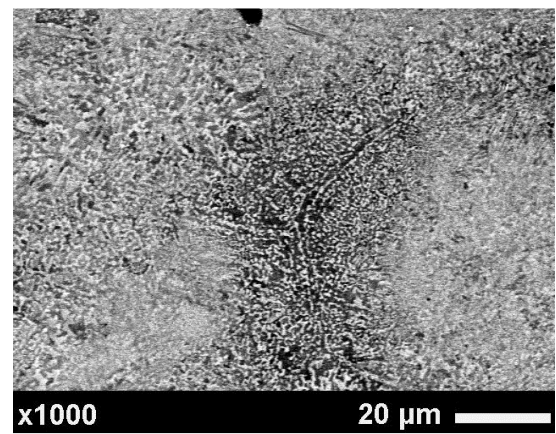

(b)

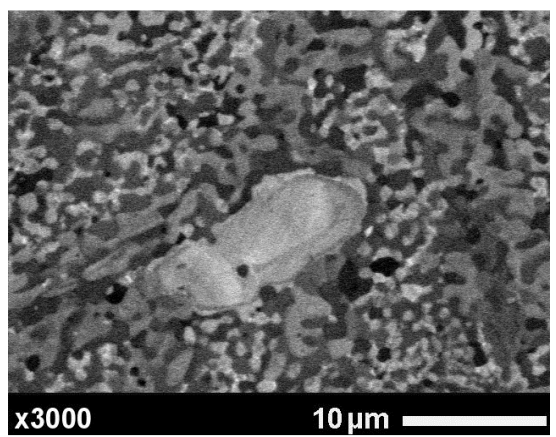

(c)

Fig. 5 - Cross-section of the N236-S8 material, sintered by SPS at $1325^{\circ} \mathrm{C}$. 
The second characteristic is the contamination by oxygen, which is either adsorbed on the particle surface and/or has not been efficiently pumped out of the inter-particle voids before the start of the sintering cycle. This may lead to a higher oxygen content of $\mathrm{Nb}_{\mathrm{ss}}$ as compared to the bulk. In fact, ICP-OES analysis revealed an overall oxygen content at least two times higher than in the atomized particles.

\section{Conclusions}

A powder of a niobium silicide based alloy, with approximate composition 47.2Nb-25.4Ti-7.5Hf1.9Cr-2.5Al-15.2Si, has been successfully atomized from a plasma melted ingot. This powder has been compacted at $1400^{\circ} \mathrm{C}$ to nearly fully dense materials by two techniques: hot extrusion (conventional technique) and spark plasma sintering (recent technique). Both materials exhibit a metastable fine (micrometer-sized) microstructure, which is less homogeneous for the SPS material than for the extruded material; the homogeneity could however be increased by adjusting the sintering parameters (e.g. by avoiding temperature overshoots) and by using more homogeneous powders. The densification of the SPS sample takes place between $c a .800^{\circ} \mathrm{C}$ and $1300^{\circ} \mathrm{C}$. A heat treatment at $1400^{\circ} \mathrm{C}$ for $24 \mathrm{~h}$ yields a coarsening and a crystallographic stabilisation, with only three phases, the $\mathrm{Nb}$ solid solution and two hP16 $\mathrm{Nb}_{5} \mathrm{Si}_{3}$ type silicide phases.

\section{Acknowledgments}

The authors acknowledge Snecma for partial support of this work, as well as the Agence Nationale pour la Recherche in the frame of the IRIS project (contract ANR-08-MAPR-0018).

\section{References}

[1] D.M. Dimiduk, M.G. Mendiratta and P.R. Subramanian in: Structural Intermetallics, ed by R. Darolia, J.J. Lewandowski, C.T. Liu, P.L. Martin, D.B. Miracle and M.V. Nathal, TMS (1993)

[2] B.P. Bewlay, M.R. Jackson, J.C. Zhao and P.R. Subramanian, Metall. Mater. Trans. 34A (2003) 2043

[3] K.S. Chan, in: Advanced structural materials: properties, design optimization, and applications, edited by W.O. Soboyejo and T.S. Srivatsan, CRC Press (2006)

[4] D.M. Herman, MSc thesis, Case Western Reserve University, OH, USA (2009)

[5] T. Murakami, C.N. Xu, A. Kitahara, M. Kawahara, Y. Takahashi, H. Inui and M. Yamaguchi, Intermetallics 7 (1999) 1043

[6] E.M. Carrillo-Heian, C. Unuvar, J.C. Jibeling, G.H. Paulino and Z.A. Munir, Scr. Mater. 15 (2001) 405

[7] Y. Kimura, H. Yamaoka, N. Sekido and Y. Mishima, Metall. Mater. Trans. 36A (2005) 483

[8] Z. Chen, Y.W. Yan, J. Alloy. Compds 413 (2006) 73

[9] S. Drawin, D. Boivin, in: Proc. Euro PM2007, Toulouse, France (2006), vol.3, 187

[10] P. Jéhanno, M. Heilmaier, H. Kestler, M. Böning, A. Venskutonis, B. Bewlay and M. Jackson, Metall. Mater. Trans. 36A (2005) 515

[11] B.P. Bewlay, M.R. Jackson and H.A. Lipsitt, Metall. Mater. Trans. 27A (1996) 3801

[12] G. Molénat, L. Durand, J. Galy, A. Couret, J. of Metallurgy 2010 (2010), article ID 145431 